\title{
TEChNOLOGICAL AND ECONOMICAL ASPECTS OF ARC WELDING OF AL 5754
}

\author{
Petar Tasic*, Ismar Hajro \& Damir Hodžić
}
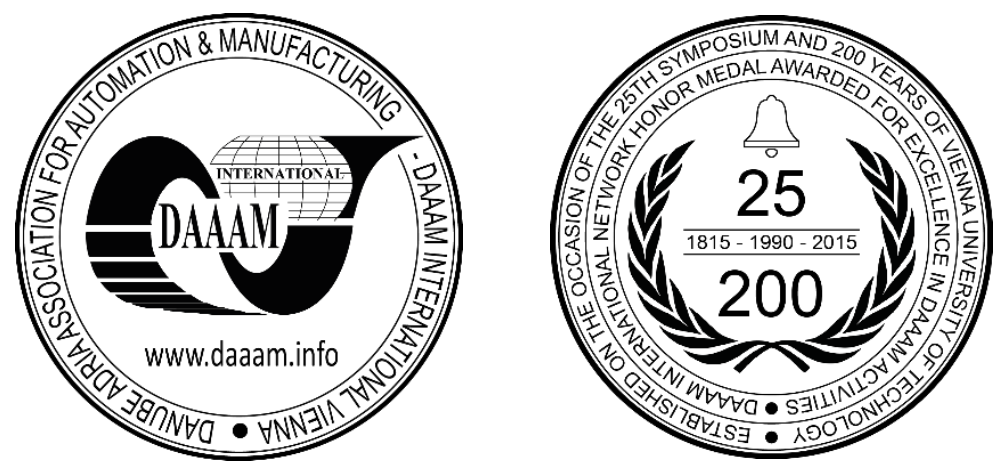

This Publication has to be referred as: Tasic, P[etar]; Hajro, I[smar] \& Hodzic, D[amir] (2017). Technological And Economical Aspects Of Arc Welding Of AL 5754, Proceedings of the 28th DAAAM International Symposium, pp.08540858, B. Katalinic (Ed.), Published by DAAAM International, ISBN 978-3-902734-11-2, ISSN 1726-9679, Vienna, Austria

DOI: $10.2507 / 28$ th.daaam.proceedings.119

\begin{abstract}
Aluminium and its alloys represent very important group of structural materials. They have many applications in mechanical and civil engineering, and welding is considered to be one of the most important joining techniques. However, welding of aluminium has several issues, like high thermal conductivity and easy formation of oxide layer with high melting temperature. Recently, solid state friction stir welding process has been developed to overcome such issues, but it is not easily applicable in every situation. Therefore, welding of aluminium still greatly relies on arc welding. Among commonly used TIG and MIG processes, pulsed MIG (and its variants) are developed to fulfil requests regarding heat input and oxide layer removal during welding. This paper gives brief general overview of technical and technological aspects of these processes, and then more details regarding welding of widely used aluminium 5754 alloy with thickness of $4 \mathrm{~mm}$. Comparison of relevant costs is given as well. All welds were made using digitally controlled equipment, while voltage and current were additionally measured. Based on evaluation of welds and calculated costs, conclusion regarding feasibility of each process is given.
\end{abstract}

Keywords: aluminium; TIG; MIG; pulsed MIG

\section{Introduction}

Aluminium and its alloys have numerous applications for mechanical and civil engineering. There are few reasons for this, but most important ones are excellent corrosion resistance to various environments, high specific strength, and great technological properties. [1] Aluminium alloys are generally easily cast, formed and machined, while joining can be done by nuts and bolts, adhesive bonding, and welding. In particular, welding is often used in automotive industry and vessel manufacturing. [2] However, welding of aluminium and its alloys is more complex than welding of most of the steels [3]. Among all reasons for this, main ones are:

- Aluminium and its alloys have excellent heat conductivity,

- In general, aluminium alloys are prone to hot cracking,

- Aluminium and its alloys have relatively low melting point, generally between 480 and $660{ }^{\circ} \mathrm{C}$,

- Aluminium forms oxide layer on surface, with melting temperature slightly above $2,000{ }^{\circ} \mathrm{C}$. 
Therefore, aluminium welding requires more detailed knowledge about alloy (in particular its chemical composition), specific equipment, precisely controlled welding conditions (i.e. welding parameters and composition of shielding gas), and well-trained welding personnel.

Many issues related to welding of aluminium and its alloys usually can be solved by precise control of heat input. If heat input is as low as possible, and as high as required, many adverse effects of welding can be avoided. That enabled solid state friction stir welding process, and its variants, to become often used to weld some aluminium alloys that previously were not easily weldable. [4,5] However, this process still has certain disadvantages, leaving significant part of aluminium welding industry to fusion welding processes. Two main fusion welding processes are in use nowadays for aluminium and its alloys, tungsten inert gas welding (TIG or GTAW) and metal inert gas welding (MIG). [2] MIG process has evolved into several variants, each offering some advantages. The idea is to reduce heat input and avoid problems induced by it. [6] This is achieved by using digitally controlled heat sources, automatization, and welder/operator training. However, it requires significant investment in equipment and training. [7] Thus, it is necessary to carefully evaluate feasibility of such investment of each case of welding, independently and ubiasedly. The problem is to conclude when, and under which conditions, it is justified to use such unconventional equipment to make welds.

\section{TIG and MIG welding processes}

There are two main fusion welding processes used nowadays for welding of aluminium and its alloys, TIG and MIG. Both are using inert gases (usually argon, helium and their combinations) to shield the weld pool. Beside these, there are few other fusion processes applicable to aluminium, but they are used in specific situations and/or configurations. [3]

TIG process is still predominantly manual welding process, highly dependent on welder's skills. It is often used where no other option is available, mostly in individual manufacturing, on-site and in shop floor conditions. Despite certain advantages, this process is slow, having very low deposition rate.

MIG process is mechanized by default, and used mostly in serial or mass production. Nevertheless, it can be used in individual production. It has significantly higher deposition rate than TIG. Several modifications of MIG process have been developed, but important one is pulsed MIG. [6] It is a variant of the conventional MIG welding process in which the current is pulsed. Pulsing was introduced to control metal transfer at low mean current levels by imposing shortduration high-current pulses. [8] The cycle consists of applying the repeated pulse current over a constant background current, as illustrates Figure 1. Background current can be as low as $15 \mathrm{~A}$.

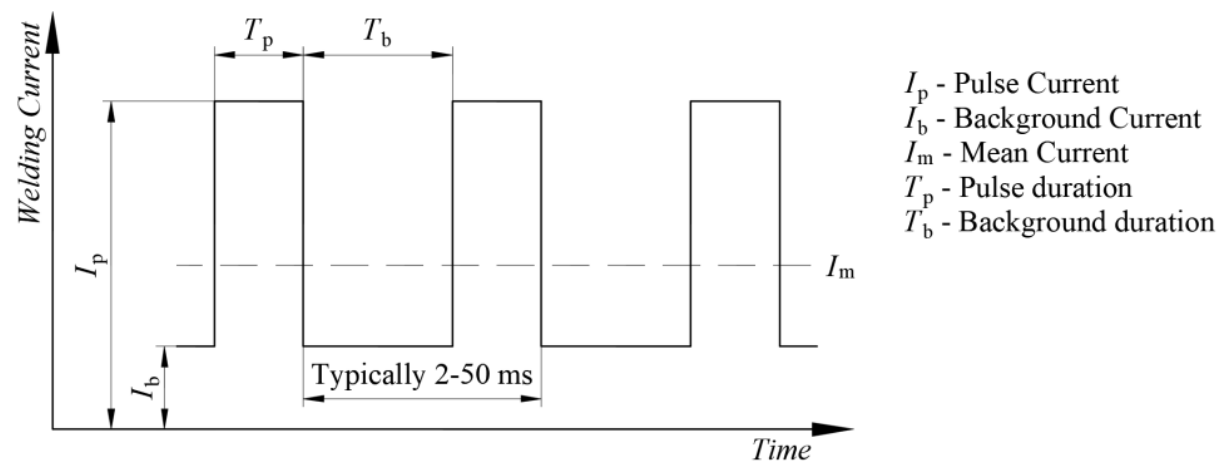

Fig. 1. General principle of pulsed MIG [8]

Modern welding sets permit the use of a wide range of pulse amplitudes, durations and waveforms at frequencies from a few Hertz to a few hundred Hertz. Pulse amplitude and duration are best combined to melt and detach a single droplet of the same/slightly smaller diameter as the electrode wire. Selection of pulse parameters for a given wire feed speed is a complex operation. Pulse height and duration are a function of wire composition, diameter and, to a lesser extent, shielding gas composition. Pulsing must provide enough heat to melt filler material (wire) and to detach exactly one drop of molten metal per pulse.

Generally, advantages of pulsed MIG welding are [8]:

- It allows the use of smooth, spatter-free welding at mean currents, which would otherwise be too low for all except dip transfer with its irregular transfer and associated spatter.

- Pulsing can extend spray operation below and through the natural transition from dip to spray where globular transfer would normally occur.

- Pulsed transfer is midway between spray transfer and dip transfer mechanism, which can be too 'cold' (due to noncontinuous arcing, the arc effectively 'goes out' between each melting cycle). This makes it ideal for welding of thicker sections where more heat is needed but for which spray transfer is still too 'hot'.

- Pulsed MIG allows welding at higher deposition rates for all positions where dip or spray transfer is not applicable.

Pulsed MIG is used mainly for welding of aluminium and stainless steel [8]. Since this process uses advanced electronics to control process, it is not economical to use where cheaper alternatives are available. Different manufacturers of welding equipment use various brand name for pulsed MIG, but the principle is the same [6,9]. 
As possible to see, pulsed MIG offers advantages when welding aluminium. It yields the lowest possible heat input, and most of the issues regarding unnecessarily high heat input are avoided. However, it has also few disadvantages. Production rate (meters of weld per minute) is lower than with dip transfer (i.e. MIG) due to decrease of wire feed rate as heat input increases, and there are limitations regarding usage of shielding gases in comparison with dip transfer. [10]

\section{Experiment}

To compare feasibility of TIG, MIG and pulsed MIG welding, an experiment has been conducted. Samples of aluminium plates were welded, and visually examined afterwards. This ensures that all welds have comparable quality. Based on measured parameters, costs are calculated.

Although primary intention was to compare only MIG and pulsed MIG, it is decided to include TIG as well, since it is commonly used process for these base and filler materials. The investment in welding equipment and welder training is not considered here, because it can vary significantly from one manufacturer to other.

\subsection{Welding of samples}

Sheets of aluminium alloy 5754 (chemical composition given in Table 1) with thickness of 4 mm were welded.

\begin{tabular}{|c|c|c|c|c|c|c|c|c|c|}
\hline & \multicolumn{9}{|c|}{$\%$ wt. } \\
\cline { 2 - 10 } & $\mathbf{M g}$ & $\mathbf{M n}+\mathbf{C r}$ & $\mathbf{M n}$ & $\mathbf{S i}$ & $\mathbf{F e}$ & $\mathbf{C r}$ & $\mathbf{Z n}$ & $\mathbf{T i}$ & $\mathbf{C u}$ \\
\hline 5754 & $2.60-3.60$ & $0.10-0.60$ & 0.50 & 0.40 & 0.40 & 0.30 & 0.20 & 0.15 & 0.10 \\
\hline
\end{tabular}

Table 1. Chemical composition of Al 5754 [11]

For each process several horizontal fillet welds were made, each $120 \mathrm{~mm}$ long, without weld preparation. All welds are made as single-pass. Table 2 gives data about filler materials for welding processes. They have been chosen according to recommendations of welding equipment or filler material manufacturers. Filler material for TIG process is Al 4043 wire (diameter $2.0 \mathrm{~mm}$ ), and for MIG and pulsed MIG it is $\mathrm{Al} 5356$ wire (dimeter $1.2 \mathrm{~mm}$ ).

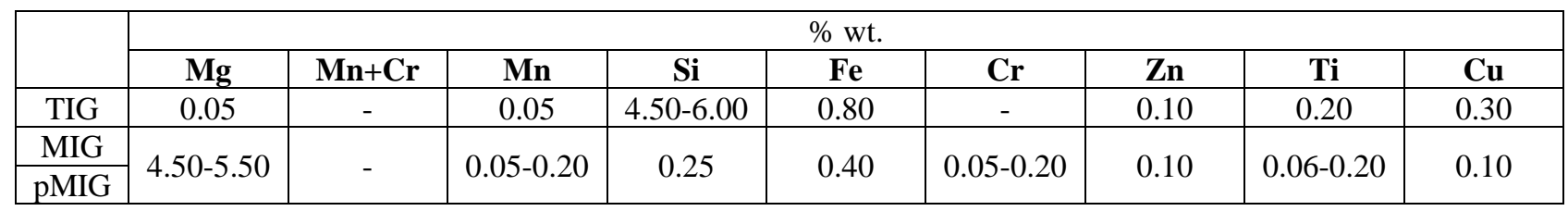

Table 2. Chemical composition of filler materials [12,13]

All welds were made in the laboratory, simulating shop floor conditions. Welding parameters were taken from welding procedure specifications where available, while other were chosen according to recommendations from either welding equipment or filler material manufacturer. They are given in Table 3. Shielding gas for all processes is argon.

\begin{tabular}{|c|c|c|c|c|}
\hline & Current, $\mathbf{A}$ & Voltage, $\mathbf{V}$ & Wire dimeter, $\mathbf{~ m m}$ & Shielding gas, $\mathbf{l} / \mathbf{m i n}$ \\
\hline TIG & 90 & 12.0 & 2.0 & 18 \\
\hline MIG & 150 & 21.5 & 1.2 & 20 \\
\hline pMIG & 105 & 19.5 & 1.2 & 20 \\
\hline
\end{tabular}

Table 3. Welding parameters [11-13]

Prior to welding, aluminium sheets were cleaned with trichloroethylene, rinsed with distilled water, dried, and then cleaned with stainless steel brush. [14]

In this way, parameters for all evaluated processes are as close to each other as possible, yet within recommended boundaries. Therefore, it is possible to make fair comparison of weld quality, efficiency and price.

\subsection{Examination of samples}

This step is required to ensure that all welds have comparable quality level in accordance with ISO 10042 (Welding - Arc-welded joints in aluminium and its alloys - Quality levels for imperfections). Welds were evaluated visually after welding and, additionally, cross-sections were cut from each weld to evaluate weld geometry and porosity. Samples were visually examined in accordance with ISO 17637 (Non-destructive testing of welds — Visual testing of fusionwelded joints). Macro sections have been prepared and examined in accordance with ISO 17639 (Destructive tests on welds in metallic materials - Macroscopic and microscopic examination of welds). 
Most importantly, no cracks have been detected in welds. After cutting and polishing of cross-section specimens, porosity has been found only in MIG welds, with dimensions that correspond to quality level B and coverage of approximately $0.5 \%$. Geometry of welds has been examined as well. All welds are symmetrical, with properly made root and full penetration. No root gap or excessive convexity has been detected.

It should be noted that ISO 10042 governs significantly more imperfections than examined in this study, but not all of them are always required to be analysed. Also, there are some imperfections not described or defined, e.g. spattering. Only MIG welds had some spattering, while no other welds had other imperfections described by ISO 17637.

Aesthetically, all welds look acceptable, but it should be noted that this is rather subjective evaluation. TIG welds are superior. Welds made with pulsed MIG are slightly behind, and welds made with MIG are last (due to spattering).

\subsection{Calculation of welding costs}

Welding costs are one of the most important and limiting factors of application of certain welding process. A rather simple method has been employed to calculate welding costs of three chosen processes. [15,16] Simple method has been chosen since it is illustrative enough, yet avoiding relatively complicated cost calculation with amortization rates and additional expenses. Later, costs will be shown as relative to each other and mutually compared.

Costs calculated in this study include only direct costs of filler material, shielding gas, electricity and welder. As mentioned before, investments required for equipment and welder's training are not included. Costs of pre-heating and post-weld heat treatment are not included as well.

All costs were calculated using parameters measured during and after welding. Current and voltage were measured by independent devices. Weight of deposited metal has been determined by weighing samples before and after welding. Shielding gas flow was measured at reduction valve (TIG) and welding apparatus (MIG and pulsed MIG).

\section{Results and discussion}

As demonstrated, it is possible to successfully utilize all three analysed fusion welding processes of aluminium alloy 5754 in given conditions. Regarding filler metal, it is enough to follow recommendations of their manufacturers. There is enough sources that recommend welding parameters (available welding procedure specifications, equipment and filler material manufacturers). Generally, this should not be concern when welding easily weldable and widely used aluminium alloy. Problems are likely to occur when welding rather obscure and rare aluminium alloy.

All three processes gave similar weld quality. After visual examination of welds and cross-sections, no unacceptable imperfections have been found. Based on examination done, all welds could fit into class B (highest quality class) according to ISO 10042. The only difference in welds is subjective, and it considers aesthetical appearance of welds. Considering this as criteria, TIG has the best look, while MIG, due to spattering, has the worst. However, all of them are acceptable. It can be concluded that all three analysed processes give adequate weld quality under described conditions.

Analysing welding costs shown that values of MIG and pulsed MIG are similar, while those for TIG are generally higher. To illustrate that, Figure 2 shows total costs of welding and costs of welder, while Figure 3 shows costs of filler material and shielding gas. Relative scaling is applied, where the most expensive process represents $100 \%$.

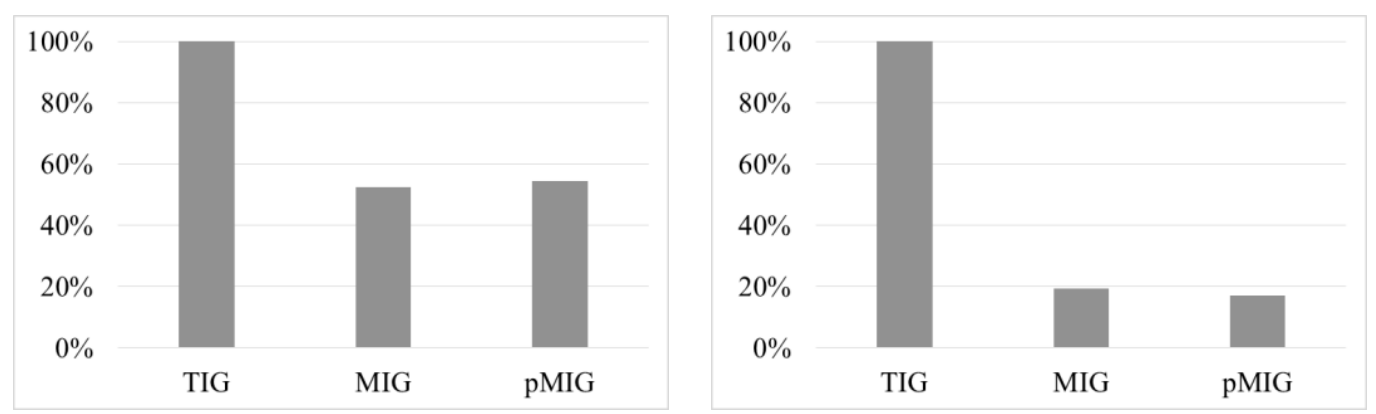

Fig. 2. Total costs of welding and costs of welder

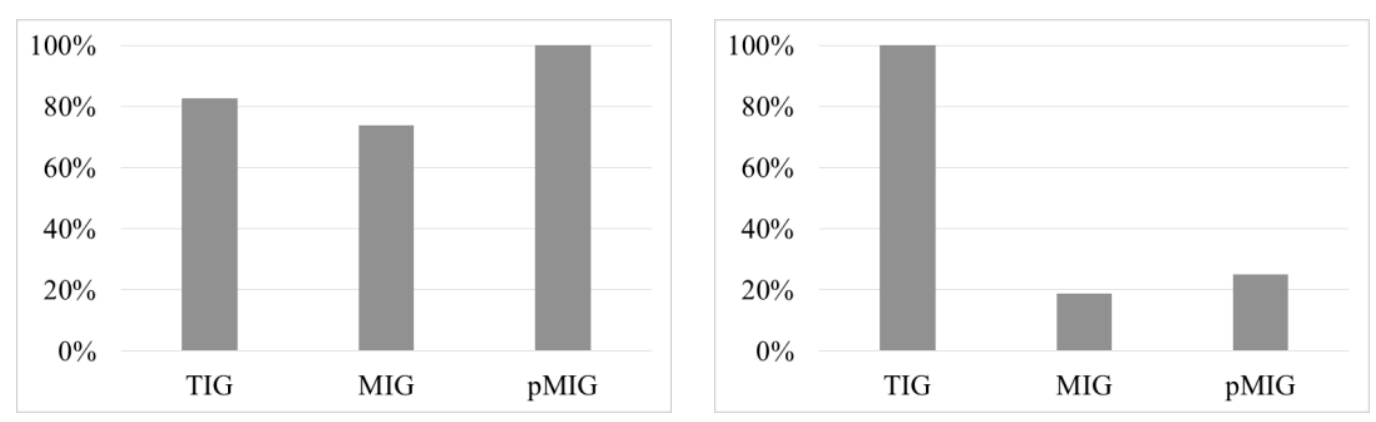

Fig. 3. Costs of filler material and shielding gas 
As noticeable, TIG has the highest welding costs. That is mainly because it is fully manual process, with very low deposition rate. That significantly increases welding time (arc time) leading to increased costs of welder and shielding gas. However, it has slightly lower costs of filler material. This is because there is no spattering and because it is partly autogenous welding process (i.e. filler material is not absolutely necessary all time). However, TIG would not be used for this weld anyway. Here is included to show more superior characteristics of MIG and pulsed MIG when applied for considered conditions. Deposition rates, which can be obtained through welder's costs (Figure 2), of MIG and pulsed MIG are close. So are the total welding costs.

It is necessary to bear in mind that this evaluation does not include expenses required for equipment and training. If that is taken into account, pulsed MIG costs would go significantly higher.

\section{Conclusion}

There are several fusion welding processes applicable for welding of aluminium alloy 5754. Among others, there are MIG, TIG and pulsed MIG, latter offering significant advantages regarding heat input. However, more factors should be considered when evaluating feasibility of certain welding process (e.g. costs and production time). To evaluate abovementioned processes, an experiment has been conducted. Plates of aluminium alloy 5754 with thickness of 4.0 mm have been welded and welds examined. Based on information obtained through this experiment, feasibility in given conditions has been estimated. All three processes have similar output, with welds of acceptable quality and look. Subjectively, TIG welds have the best appearance, with pulsed MIG slightly behind. However, pulsed MIG requires significantly higher investment in equipment and training than other two processes. MIG and pulsed MIG shown similar deposition rates and costs for sheets of average thickness (e.g. $4 \mathrm{~mm}$, as in this study), so it can be concluded that the most feasible process in this case would be MIG. Advantages offered by pulsed MIG could be visible in other conditions. That includes thin aluminium sheets (e.g. $1 \mathrm{~mm}$ ), specific welding positions, or specific products where heat input is strictly limited (e.g. measuring equipment). Further research, including welding of other aluminium alloys, could confirm this by conducting similar experiment.

\section{References}

[1] Kuruc, M., Zvončan, M., Peterka, J. (2014). Investigation of Ultrasonic Assisted Milling of Aluminum Alloy AlMg4.5Mn, in: Proceeding of 24th DAAAM International Symposium on Intelligent Manufacturing and Automation, Procedia Engineering, Vol. 69, 2014, pp. 1048-1053. doi: 10.1016/j.proeng.2014.03.089

[2] Müller, U. (2011). Introduction to Structural Aluminium Design, Whittles Publishing, ISBN 978-184-99-5007-7, Dunbeath

[3] Zaki A. [Ed.] (2012). Aluminium Alloys - New Trends in Fabrication and Applications, InTech, ISBN 978-953-510861-0, Rijeka, doi: 10.5772/3354

[4] Casalino, G., Campanelli, S., Mortello, M. (2014). Influence of Shoulder Geometry and Coating of the Tool on the Friction Stir Welding of Aluminium Alloy Plates, in: Proceeding of 24th DAAAM International Symposium on Intelligent Manufacturing and Automation, Procedia Engineering, Vol. 69, 2014, pp. 1541-1548. doi: 10.1016/j.proeng.2014.03.153

[5] Mishra, R. S., Ma Z. Y. (2005). Friction stir welding and processing, Materials Science and Engineering R, Vol. 50, 2005, pp. 1-78.

[6] Horvat M., Kondić V. (2012). The examples of modified procedures of MIG/MAG welding, Tehnički glasnik, Vol. 6, No. 2, 2012, pp. 137-140.

[7] Rosado T., Almeida I., Pires I., Miranda R., Quintino L. (2008). Innovations in arc welding, Proceedings of 5. Congresso Luso-Moçambicano de Engenharia, Maputo, 2-4 September 2008.

[8] http://www.twi-global.com (2017). What is Pulsed MIG/MAG welding and what are its advantages over conventional MIG/MAG processes?, Accesed on 2017-07-16

[9] Brown, E. (2017). An Introduction to Pulsed GMAW, Welding Journal, Vol. 96, No. 2, 2017, pp. 76-78.

[10] Lincoln Electric (2017). AC Aluminum Pulse (GMAW) Weld Process Guide, Identification code TE12.010

[11] AlcoTec (2015). AlcoTec Aluminum Technical Guide, Identification code ALC-10029B

[12] AlcoTec (2017). Alloy 4043 weld data sheet

[13] AlcoTec (2017). Alloy 5356 weld data sheet

[14] Carriere, M. D. (2017). Preparing Aluminum before Welding, Welding Journal, Vol. 96, No. 2, 2017, pp. 32-35.

[15] http://www.twi-global.com (2017). Welding costs, Accesed on 2017-07-18

[16] O’Brien, A. [Ed.] (2004). Welding Handobbok: Welding processes, Part 1, AWS, ISBN 0-87171-729-8, Doral 